\title{
A INDÚSTRIA FARMACÊUTICA E A IMPORTÂNCIA ESTRATÉGICA DOS PROPAGANDISTAS DE MEDICAMENTOS: ESTUDO COM COLABORADORES EM NATAL/RN
}

\author{
H. R. HEKIS ${ }^{1}$, K. C. SOUSA ${ }^{1}$, M. FURUKAVA ${ }^{2}$, R. A. M. VALENTIM ${ }^{1}$, I. D. OLIVEIRA ${ }^{1}$ e R. L. S. ALVES ${ }^{3}$ \\ ${ }^{1}$ Universidade Federal do Rio Grande do Norte - UFRN \\ ${ }^{2}$ Universidade Federal Rural do Semi-Árido - UFERSA \\ ${ }^{3}$ Instituto Federal do Rio Grande do Norte - IFRN \\ hekis1963@gmail.com
}

Artigo submetido em março/2013 e aceito em agosto/2014

DOI: $10.15628 /$ holos.2014.1341

\section{RESUMO}

A indústria Farmacêutica é um mercado competitivo, complexo e de investimentos vultosos em pesquisa, desenvolvimento e produção de produtos farmacêuticos. Uma das principais estratégias da Indústria farmacêutica é a promoção de seus produtos junto à classe médica, através dos propagandistas de medicamentos, profissionais essenciais ao sucesso desta estratégia. 0 estudo objetivou comprovar a importância estratégica dos propagandistas de medicamentos e as competências necessárias para o bom desempenho desta profissão, de forma a garantir maior vantagem competitiva, e o sucesso destas organizações. Foram realizadas entrevistas individuais e semi-estruturadas e uma reunião de brainstorming, resultando na identificação de 46 competências, entre conhecimentos, habilidades e atitudes, que os propagandistas atribuíram maior importância, sendo assim consideradas mais relevantes e essenciais para o desempenho das atividades dos propagandistas farmacêuticos sob suas perspectivas.

PALAVRAS-CHAVE: Indústria farmacêutica, Marketing farmacêutico, Propagandistas Vendedores de Medicamentos.

\section{THE PHARMACEUTICAL INDUSTRY AND THE STRATEGIC IMPORTANCE OF THE PROPAGANDISTS OF DRUGS: STUDY WITH EMPLOYEES IN NATAL/RN}

\begin{abstract}
The Pharmaceutical industry is a competitive, complex and major investment in research, development and production of pharmaceutical products. One of the main strategies of the pharmaceutical industry is the promotion of their products to the medical profession, through propagandists medicines, essential to the success of this strategy professionals. The study aimed to demonstrate the strategic importance of the propagandists of medicines and necessary for the proper
\end{abstract}

performance of this profession skills, to ensure competitive advantage, and the success of these organizations. Semi-structured individual interviews, and a brainstorming meeting were held, resulting in the identification of 46 competencies, including knowledge, skills and attitudes which the propagandists attributed greater importance and therefore were deemed most relevant and essential to the performance of activities of pharmaceutical propagandists under its prospects.

KEYWORDS: Use Pharmaceutical industry, Pharmaceutical Marketing, Drug Propagandists sellers. 


\section{INTRODUÇÃO}

O mercado farmacêutico é um dos mais competitivos, complexos, rentáveis e inovadores da atualidade. Neste mercado atuam grandes corporações mundiais, que chegam a investir bilhões de dólares no desenvolvimento e comercialização de seus produtos (DAS, 2011). A pesquisa, o desenvolvimento e a produção de medicamentos são fundamentais para a manutenção da saúde das pessoas. Este é um mercado em que o consumidor do produto nem sempre o escolhe, pois na maioria das vezes quem define o produto a ser usado pelo paciente, é o médico, que prescreve o medicamento que ele avalia ser o mais adequado. Kremer et al., (2008) defendem que os recursos direcionados ao marketing farmacêutico se justificam por possibilitarem aos fabricantes farmacêuticos mais inovadores, a oportunidade para recuperar seus altos investimentos com Pesquisa e Desenvolvimento ( $P \& D)$, servindo inclusive como um canal de comunicação para educar os médicos e expor aos consumidores as informações que podem melhorar os resultados de saúde, e para isso realizam ações promocionais e comerciais juntos aos médicos que são os prescritores dos medicamentos e junto aos canais de distribuição competentes (farmácias, distribuidores) buscando alcançar os objetivos planejados.

Com a expansão da economia e a globalização, as empresas que atuam no mercado farmacêutico deslocaram seus investimentos para várias partes do globo, especialmente os países em desenvolvimentos, também chamados de BRIC'S, visando se aproximar dos mercados consumidores (CIVANER, 2012).

No Brasil, observa-se o aumento de investimentos destes laboratórios farmacêuticos, à medida que aumenta o poder aquisitivo da população. Com a chegada de novos laboratórios, observa-se também um aumento na oferta de oportunidades de trabalho, especialmente para a área do marketing farmacêutico, e para os propagandistas vendedores de medicamentos, que são os profissionais responsáveis pela geração da demanda de medicamentos, através das visitas que fazem aos médicos.

É importante ainda destacar, o aumento do nível de exigência das empresas, buscando profissionais cada vez mais competentes e "identificados com este mercado". Diante de tais fatores e para a organização acompanhar as mudanças do mundo do trabalho, Kobayashi (2010) afirmam que os profissionais devem ser cada vez mais qualificados, atualizados, de forma que os investimentos realizados revertam para manutenção da saúde e competitividade da organização.

A problemática a ser questionada refere-se à importância estratégica dos propagandistas de medicamentos e quais as competências necessárias para trabalhar neste mercado, de forma a contribuir para a competitividade das empresas farmacêuticas. Dessa forma o presente artigo tem por objetivo comprovar a importância estratégica destes profissionais e identificar as competências necessárias aos profissionais da propaganda médica, e delineados os seguintes objetivos específicos: identificação de competências individuais; classificação de competências em conhecimentos, habilidades e atitudes; e caracterização das atividades dos propagandistas.

O artigo está estruturado da seguinte maneira, a primeira seção trata da introdução, a segunda seção versa sobre a fundamentação teórica, com destaque para estratégia, recursos humanos e competências, a terceira seção apresenta a metodologia, a quarta seção traz a discussão 
e os resultados da pesquisa, a quinta seção apresenta as considerações finais e, em seguida, são relacionadas as referências utilizadas.

\section{ESTRATÉGIA, RECURSOS HUMANOS E COMPETÊNCIAS}

Em mercados altamente competitivos como o da indústria farmacêutica, Porter (1980) destaca que as empresas enfrentam fortes pressões dos órgãos reguladores governamentais, das associações profissionais, das redes sociais, bem como a pressão competitiva de seus concorrentes, além é claro da necessidade de desenvolver e comercializar o mais rápido possível seus produtos, em razão das patentes concedidas para a pesquisa.

Mintzberg et. al., (2008) assinalam que ocorre uma influência mutua entre as organizações e as estratégias, e que as estratégias são constituídas a partir de arcabouço organizacional já existente; podendo ser reavaliada em um dado momento pela gestão estratégica. Isto pode ser condicionado, tanto pela necessidade de mudança como pela sobrevivência da organização.

Assim, a administração estratégica exerce um papel importante na caracterização dos diversos e complexos processos organizacionais, contribuindo para a criação de uma gestão focada na eficiência e na busca de melhores resultados. Assim observa-se que há uma importante relação entre a gestão estratégica de uma organização e às realidades da organização. Portanto, os seus pontos fortes e fracos, as suas oportunidades e ameaças devem ser consideradas como ponto de partida para a formação de uma nova estratégia para a gestão.

Empresas escolhem estratégias voltadas para atender necessidades internas e externas, quando as estratégias adotadas são voltadas para atender as necessidades dos clientes, é preciso que o público alvo seja bem definido, a fim de melhor atendê-lo, mesmo considerando que estas necessidades mudam rapidamente. (ZHOU, BROWN, DEV, 2011). Davies et. al., (2010) evidencia que uma boa estratégia para melhor atender as necessidades de seus clientes é a introdução de práticas de gestão de relacionamento, a fim de "correspondê-los".

Com relação às estratégias de marketing adotadas Green, Whitten e Inman (2012) evidenciam que quando a organização direciona estas estratégias a fim de atender novas perspectivas do mercado, mesmo com o foco para o cliente, observa-se a necessidade destes participes do mercado serem rápidos para se adaptar a nova realidade. Neste mesmo sentido, Morgam (2012) destaca que o uso apropriado e eficaz de estratégias de marketing aliada ao bom planejamento estratégico favorece ao sucesso das organizações.

Wright e Mcmahan (2011) evidencia que nesses ambientes competitivos, os recursos humanos das empresas se tornam mais importantes para o sucesso das organizações. Uma importante ação a ser adotada pelas organizações, buscando melhorar o seu desempenho é a gestão estratégica dos recursos humanos, que segundo Guest (2011) tem um impacto direto e positivo sobre desempenho da organização.

Neste mesmo sentido, Khaliq et al., (2011) afirma que um dos principais objetivos da gestão estratégica de recursos humanos é o desenvolvimento de melhores práticas para gerar altos níveis de comprometimento e desempenho nas pessoas, buscando desenvolve-las e assim contribuir de forma efetiva para tornar a organização mais competitiva. 
Desenvolver pessoas é torna-las mais competentes, através do desenvolvimento de conhecimentos, habilidades e atitudes, que as façam mobilizar essas competências no momento exato, para a resolução de um problema específico, para a consecução de determinado objetivo, em fim, em busca do alto desempenho profissional. (FLEURY e FLEURY, 2004).

Segundo Wood Júnior e Picarelli Filho (2004, p. 106), os conhecimentos "constituem um conjunto de conceitos, técnicas, teorias e metodologias relacionadas ao trabalho. É o saber adquirido, que pode ser transmitido e aprendido." Os mesmos autores conceituam habilidade como "a capacidade de realizar uma tarefa ou um conjunto de tarefas em conformidade com determinados padrões exigidos pela organização." As atitudes estariam relacionadas à capacidade do indivíduo de aplicar os conhecimentos e as habilidades que possui em seu ambiente de trabalho.

Le Boterf (2003) defende que, por abarcar conhecimentos, habilidades e atitudes, a competência é algo que pressupõe um contínuo movimento, uma mobilização constante de diversos saberes para aplicação a uma situação específica. Segundo esse autor, a competência é sempre uma "competência para" alguma coisa.

Dessa forma, a estratégia surge vinculada às competências da empresa, enquanto o seu desdobramento em competências atravessa níveis hierárquicos e equipes de trabalho. A efetividade da organização resulta da capacidade de articular o seu direcionamento estratégico com as competências da empresa, dos grupos e as competências individuais. Portanto, estabelecer o direcionamento estratégico, alinhado a competências organizacionais e desdobrado em competências, sugere pensar sobre a cultura organizacional e o modelo de gestão (MOURA e BITENCOURT, 2006).

Para o presente estudo, considera-se competência como um conjunto de conhecimentos, habilidades e atitudes que proporcionam ao profissional - neste caso, o propagandista vendedor de medicamentos - um melhor desempenho de suas atribuições funcionais com eficiência no desenvolvimento das atividades e eficácia nos resultados do trabalho.

Assim as organizações situadas em ambientes competitivos precisam definir a sua estratégia e as competências necessárias para implementá-las, num processo de aprendizagem permanente. Para este processo é importante compreender que não existe uma ordem de precedência, mas um círculo, em que uma alimentaria a outra mediante o processo de aprendizagem. (FLEURY e FLEURY, 2004).

\subsection{Competências individuais}

Competências individuais são aquelas que dizem respeito a cada um dos profissionais da organização. São as competências que o indivíduo possui por sua formação educacional, por sua criação familiar, por sua biografia Já as competências de negócio referem-se à compreensão que um indivíduo deve ter em relação ao "negócio" da organização, aos objetivos organizacionais, assim como uma compreensão do ambiente político e social que cerca a organização (ZARIFIAN, 2001).

Neste sentido o bom profissional deve incorporar competências, ou aperfeiçoar as que já possuem, de acordo com a sua vivência no ambiente de trabalho. Assim, percebe-se que há uma troca entre a organização e as pessoas, onde os dois lados têm participação efetiva no processo de crescimento profissional, gerando benefícios para ambos, pois a melhor capacitação dos 
profissionais pode se traduzir num melhor desempenho de seu trabalho, aumentando a produtividade.

Assim sendo, a responsabilidade profissional aparece mais uma vez como fator preponderante para o desenvolvimento das competências do indivíduo. Além disso, os profissionais de qualquer área precisam de autonomia para a tomada de decisões, visto que estarão se deparando continuamente com situações não planejadas ou que fogem à rotina do trabalho.

\subsection{Gestão por competências}

O conceito de competências essenciais das organizações surgiu com Prahalad e Hamel (2004), na década de 1990. Essas competências são um conjunto de habilidades e tecnologias que resultam por aportar um diferencial fundamental para a competitividade da empresa. A identificação e o desenvolvimento de competências são fatores indispensáveis para que a organização possa definir suas estratégias de atuação frente a um mundo complexo e em constante transformação.

Prahalad e Hamel (2004) argumentam ainda, que as empresas podem identificar um número relativamente pequeno de competências básicas que lhes dão uma vantagem estratégica sustentável no mercado. A gestão de competências ganha importância e é percebida como um modelo gerencial derivado da Teoria da Gestão Baseada em Recursos, dando ênfase aos indivíduos que trabalham nas organizações, como atores determinantes para aumentar a sua competitividade.

Bitencourt (2006) assinala que os elementos que se destacam no desenvolvimento de competências podem ser resumidos e associados ao desenvolvimento de conceitos, habilidades e atitudes. Sendo assim, demandam capacitação e se traduzem na capacidade de mobilizar recursos em práticas de trabalho; implicam em articular recursos e servem de incentivo visando melhores desempenhos. Além disso, produzem questionamento constante e desencadeiam um processo de aprendizagem individual, na qual a responsabilidade maior deve ser atribuída ao próprio indivíduo. Desse modo, as competências são transferidas e consolidadas por meio do relacionamento com outras pessoas (interação).

\subsection{Modelos e técnicas para identificação de competências}

A Gestão de Competências pode ser um importante instrumento para a identificação das necessidades de conhecimentos individuais e institucionais, e o consequente desenvolvimento das pessoas com vistas ao alcance dos objetivos organizacionais. Podem ser utilizadas em organizações públicas e privadas, por meio da aplicação de diferentes modelos, técnicas e métodos, o que exige que as empresas e os profissionais desenvolvam competências essenciais necessárias para conviver e trabalhar. Neste sentido, o estudo das competências essenciais apresenta-se como uma importante estratégia para a busca do aumento da competitividade de qualquer organização no mercado.

Diversos autores, entre eles Fleury e Fleury (2004) e Dutra (2004) destacam a importância do Gerenciamento baseado nas competências. Dois modelos americanos: o American Society for Training and Development - ASTD e o Competency-Based Management foram os primeiros a serem destacadas, para identificação das competências. 
Depois de mapeadas as competências, devem ser identificadas aquelas que serão objeto de ações de desenvolvimento. O Gerenciamento Baseado nas Competências busca identificar os padrões de eficácia visíveis nas ações praticadas pelos funcionários mais eficazes.

As pesquisas na área de Gestão de Competências envolvem diferentes abordagens, compreendendo a visão de gestores, funcionários e clientes. Para a identificação de competências, as metodologias e técnicas adotadas têm como características: observação de comportamentos de funcionários de alto desempenho para delineamento de suas qualidades; uso de entrevistas focalizadas ou semi-estruturadas; técnicas de brainstorming e brainwriting; survey; e modelamento por especialistas.

\subsection{A propaganda médica - Uma estratégia da indústria farmacêutica}

A indústria farmacêutica se utiliza de diversas estratégias de marketing a fim de aumentar as suas vendas de medicamentos, nos mercados em que atua (DAS, 2011). No quadro 1 são destacadas algumas destas estratégias de marketing utilizadas pela industria farmacêutica objetivando o maior crescimento de suas vendas e manterem-se mais competitivas, frente a seus concorrentes.

Em uma sociedade capitalista, a indústria tem todo o direito de buscar aumentar a sua participação no mercado, maximizar seus lucros, e usar estratégias adequadas visando alcançar estes objetivos. A indústria farmacêutica não é diferente das demais, mesmo atuando com saúde humana, o objetivo é aumentar os seus lucros, e para isso precisa convencer os médicos a prescreverem com maior frequência os medicamentos mais caros. (BRODY, 2005).

Para isso, o marketing farmacêutico que é o responsável por produzir informações técnicas e científicas sobre novos produtos e novas descobertas para os médicos, atua de forma importante no desenvolvimento de ações estratégicas visando atingir esse objetivo.

Quadro 1: Estratégias do Marketing Farmacêutico

\begin{tabular}{|l|l|}
\hline \multicolumn{1}{|c|}{ ESTRATÉGIA } & \multicolumn{1}{c|}{ AÇÃO } \\
\hline Propaganda direta consumidor & Meios de comunicação (mídia impressa, rádio, televisão, internet etc.); \\
\hline Propaganda Médica & $\begin{array}{l}\text { Visita de Propagandistas de Medicamentos aos consultórios médicos, } \\
\text { clínicas e hospitais; }\end{array}$ \\
\hline Anúncios em Publicações & Anúncios pagos em publicações médicas, não médicas, revistas e journals; \\
\hline Matérias imprensa leiga & $\begin{array}{l}\text { Matérias escritas por jornalistas veiculando assuntos de interesse da } \\
\text { Indústria farmacêutica; }\end{array}$ \\
\hline Merchandising & $\begin{array}{l}\text { Propaganda de modo ostensivo ou subliminar de um produto } \\
\text { (medicamentos). Muito utilizado em filmes e novelas }\end{array}$ \\
\hline Eventos Médicos & Realização de reuniões, simpósios e patrocínio de congressos médicos. \\
\hline
\end{tabular}

Fonte: Dos autores, baseado em (WAZANA, 2000; FUGH, 2007; PALÁCIOS, 2008; GAGNON, 2008; SANVITO, 2012)

E estas estratégias são realizadas pela força de vendas da indústria farmacêutica, os propagandistas vendedores de medicamentos ou representantes farmacêuticos, que são considerados o principal elo entre a indústria e os médicos. Esses profissionais são contratados, treinados, avaliados e remunerados para atender os interesses das empresas farmacêuticas (BRODY, 2005).

Os representantes farmacêuticos ou propagandistas de medicamentos que visitam os médicos para promover seus medicamentos e convidam os médicos para jantares e distribuem 
canetas, e outros presentes visando influenciar médicos para prescrever seus produtos mais que os das empresas concorrentes. Esta estratégia de Marketing claramente eficaz e é comum em um ambiente de um mercado altamente competitivo. Neste sentido surgem algumas dificuldades, a partir de diferentes crenças e valores e interesses existentes entre médicos, pacientes, e terceiros, incluindo a mídia e indústria farmacêutica (NEELAN, 2012).

A promoção médica realizada pelos propagandistas de medicamentos junto aos médicos e outros profissionais de saúde, a fim de promover seus medicamentos, evidenciando suas indicações e vantagens é uma eficiente estratégia utilizada para aumentar as suas vendas e melhorar os lucros das empresas. O trabalho destes propagandistas consiste em visitar os médicos periodicamente, visando promover e propagar os produtos produzidos ou distribuídos pelas indústrias, levando informações técnicas sobre produtos existentes e novos produtos. (BRODY, 2005; MEDAWAR, 2002; WAZANA, 2000; MAGUIRE, 1999).

A Organização Mundial da Saúde (OMS) define a propaganda médica como sendo, todas as atividades informativas e de persuasão por parte dos fabricantes e distribuidores, cujo efeito é o de influenciar a prescrição, fornecimento, compra ou uso de medicamentos (NORRIS et al., 2007).

Rey (2010) evidencia que o setor farmacêutico concentra seus investimentos e seus esforços para desenvolver medicamentos para tratar doenças crônicas, que exigem prescrições contínuas, e por períodos mais longos. Já Palácios (2008) destaca que o uso de técnicas sofisticadas de propaganda e marketing e as relações estabelecidas entre médicos e representantes farmacêuticos, podem trazer danos aos usuários de medicamentos, portanto evidencia a importância da regulação da propaganda médica.

No Brasil, há uma resolução que estabelece uma distinção: para medicamento de venda direta ao consumidor, sem necessidade de prescrição médica, a propaganda pode ser dirigida ao consumidor; se houver necessidade de prescrição do medicamento (com ou sem retenção de receita), a propaganda deste só poderá ser dirigida a profissionais habilitados a prescrevê-los, em veículos restritos a estes (BRASIL, 2000, 1977).

O marketing farmacêutico e as relações entre médicos e propagandistas de medicamentos tem sido bastante discutida na literatura, evidenciando o debate sobre o confito de interesses entre os usuários de medicamentos: pacientes, e a indústria farmacêutica, que através do marketing farmacêutico planeja uma série de tecnicas de promoção e propaganda a fim de conquistar a preferência dos médicos na hora da prescrição dos medicamentos. A utilização de brindes, amostras grátis, convites para eventos, almoços, e presentes é o ponto central deste debate. (WAZANA, 2000; PALÁCIOS, 2008; GAGNON, 2008; FUGH, 2007).

\section{METODOLOGIA}

O estudo foi realizado com base em pesquisa qualitativa (entrevista semiestruturada) e aplicação da técnica de brainstorming, objetivando-se a expressão de idéias, pensamentos e opiniões pelos próprios profissionais. Do ponto de vista dos objetivos a pesquisa é caracterizada como descritiva, uma vez que visa descrever características de determinado fenômeno e estabelecer relações entre variáveis. O tipo de amostragem utilizada é não-probabilística e 
selecionada por tipicidade (VERGARA, 2000), uma vez que serão utilizados os próprios sujeitos que desenvolvem as atividades de propaganda médica no mercado de Natal.

Procurou-se adotar no presente trabalho o modelo preconizado por alguns autores (DUTRA, 2004; FLEURY, 2004), segundo o qual as competências podem ser levantadas com base em seus componentes de conhecimentos, habilidades e atitudes.

O universo da pesquisa foi composto pelos profissionais que trabalham na propaganda médica na cidade do Natal, RN Brasil. As informações sobre as competências funcionais foram coletadas baseando-se em 47 propagandistas vendedores de medicamentos, do universo de $250^{12}$, correspondendo a $18,8 \%$ dos profissionais que trabalham na propaganda médica em Natal. Estes profissionais desenvolvem seu trabalho através da visitação aos profissionais de saúde, principalmente médicos das diversas especialidades, onde promovem e divulgam produtos farmacêuticos produzidos pelas indústrias farmacêuticas.

\subsection{Entrevistas}

Como primeiro procedimento de coleta de informações sobre competências individuais foi realizado uma entrevista individual e semiestruturada com trinta e cinco propagandistas de medicamentos farmacêuticos. Para a entrevista semiestruturada, foi utilizado um roteiro composto de: cabeçalho com as informações sobre instituição de ensino, identificação do curso de pósgraduação, nome do pós-graduando e título do trabalho ao qual a pesquisa está vinculada; definições de competência organizacional e competência individual; e a questão a ser respondida: "Com base nas atividades típicas do Profissional Propagandista-vendedor, quais são as competências que você considera importante para um Propagandista vendedor".

Os trinta e cinco propagandistas foram entrevistados individualmente, em momentos e locais diferentes, de acordo com a sua conveniência. Inicialmente, foi feita uma breve explanação sobre os motivos de realização do trabalho, do que se tratava e destinava a pesquisa. Foi ressaltado que as informações fornecidas seriam utilizadas estritamente para os objetivos da pesquisa acadêmica.

\subsection{Brainstorming}

O segundo instrumento desenvolvido foi baseado na técnica de brainstorming, a fim de que fossem levantados os componentes de competências (conhecimentos, habilidades e atitudes) entre os próprios profissionais que desenvolvem as atividades de propaganda médica. Buscou-se também estimular aos profissionais fornecerem uma variedade de ideias, livres de julgamentos, acerca do problema.

A sessão de brainstorming foi realizada, no período vespertino, com a participação de 12 propagandistas vendedores de medicamentos, reunidos no SINPROVERN (Sindicato dos Propagandistas Vendedores de medicamentos do Rio Grande do Norte).

\footnotetext{
${ }^{11}$ Atuam 250 propagandistas-vendedores de medicamentos em Natal/RN(SINPROVERN)
} 
No início da sessão foram dadas informações sobre os motivos de realização do trabalho, do que se tratava e destinava a pesquisa. Foi destacado que as informações fornecidas seriam utilizadas estritamente para os objetivos da pesquisa acadêmica. Após isso, foi colocada a seguinte questão: "O que você considera que um propagandista vendedor deve conhecer saber fazer e ter atitude para fazer, para o bom exercício de suas atividades" e, em seguida, solicitado que esses profissionais emitissem suas opiniões.

\section{RESULTADOS E DISCUSSÃO}

Esta seção apresenta as Competências identificadas nas entrevistas com os propagandistas de medicamentos, bem como, Competências identificadas no brainstorming.

\subsection{Competências identificadas nas entrevistas}

Nas entrevistas, foram identificadas 46 competências, nos quesitos conhecimentos, habilidades e atitudes, conforme Quadro 2. Dentre elas, 6 competências foram consideradas relevantes pelos propagandistas, sendo citadas com frequência superior a $60 \%$ pelos entrevistados. No quesito conhecimentos, destacam-se como mais relevantes as competências: técnicas de vendas; técnicas de planejamento; técnicas de propaganda; e técnicas de negociação.

No quesito conhecimentos os itens: técnicas de negociação; técnicas de vendas; técnicas de propaganda; e técnicas de planejamento foram consideradas relevantes, obtendo mais de $60 \%$, o que indica a importância destas competências na visão dos propagandistas. Estas competências estão relacionadas ao uso do conhecimento ligadas às atividades diárias dos propagandistas, tais como: fornecer informações de forma eficaz e eficiente ao maior número possível de profissionais de saúde.

Para isso eles preparam as suas atividades, promovem seus produtos através das técnicas de propaganda, materiais promocionais, brindes, presentes a fim de obter a prescrição médica, que é fundamental para aumento das vendas e consequente alcance das metas planejadas pela empresa.

É importante ainda destacar que as empresas farmacêuticas trabalham estas competências de forma frequente em seus treinamentos, fornecendo esses conhecimentos técnicos aos seus profissionais, buscando transformar essas competências individuais em competências úteis à organização.

Outra competência que também foi identificada foi composição de produtos, em que os entrevistados acreditam que é essencial se conhecer a composição farmacêutica dos produtos, para poder dialogar, informar e convencer os médicos, a prescreverem seus medicamentos.

No quesito habilidades foram destacadas as competências: boas relações humanas e a capacidade de comunicação, com um percentual acima de $60 \%$. Os resultados apontam para uma preocupação dos profissionais com a forma que se comunicam e de como se relacionam com seus clientes.

Fica evidente a importância atribuída pelos profissionais propagandistas às habilidades de relacionamento pessoal e de comunicação, competências ligadas as suas atividades diárias. Com 
base nesses dados percebe-se que conhecer e saber lidar com pessoas é bastante importante para o bom desempenho desta profissão, assim como conhecer e saber se comunicar de forma clara, concisa e com transparência para com seus clientes.

Neste mesmo quesito, cabe considerar a importância percebida pelos propagandistas as seguintes competências: trabalhar sobre pressão; capacidade de criar; boa memória; capacidade de síntese de ideias; e capacidade de tomar decisões, que também são consideradas relevantes, apesar de terem recebido um score menor, na visão dos profissionais.

A questão da habilidade das pessoas em trabalhar sob pressão é uma das novas realidades do mundo moderno, e na indústria farmacêutica é bastante evidenciado, em razão da grande competição e dos altos investimentos em pesquisa e desenvolvimento realizado, pelas empresas, e que estabelecem metas para que sejam alcançadas pelos seus colaboradores em busca da maior rentabilidade.

No quesito atitudes nenhuma competência alcançou o score de 60\%. Entretanto, empatia, ética profissional e iniciativa obtiveram $54 \%$ e a integridade $51 \%$, sendo assim as competências mais citadas.

As competências: ética profissional e integridade, também foram consideradas relevantes, o que evidencia a preocupação destes profissionais com as questões de conduta profissional e as relações com médicos, colegas e pacientes. A questão da ética tem ganhado bastante atenção, em razão das discussões que têm sido levantadas, por pesquisadores e estudiosos com relação dos limites e das condutas aceitáveis dos profissionais propagandistas de medicamentos, na busca do convencimento dos médicos para a prescrição médica, e inclusive através do fornecimento de amostras grátis, brindes, presentes e prêmios em troca da prescrição.

Outra competência que vale a pena destacar é a Empatia, que também é considerada como uma competência bastante relevante, demonstrando que os profissionais associam a questão da empatia com o melhor desempenho de suas funções.

Quadro 2: Demonstrativo das entrevistas com 35 Propagandistas de Medicamentos

\begin{tabular}{|l|c|}
\hline \multicolumn{1}{|c|}{ CONHECIMENTOS } & Importância \% \\
\hline Técnicas de Vendas & $77 \%$ \\
\hline Técnicas de Planejamento & $71 \%$ \\
\hline Técnicas de Propaganda & $66 \%$ \\
\hline Técnicas de Negociação & $60 \%$ \\
\hline Língua Estrangeira & $54 \%$ \\
\hline Composição dos produtos & $54 \%$ \\
\hline Informática e Internet & $49 \%$ \\
\hline Boas Maneiras & $43 \%$ \\
\hline Relações humanas, normas sobre a profissão, técnicas de memorização, Noções de & Menor que 40 \% \\
\hline saúde humana, Cortesia, Bom Português. & Importância \% \\
\hline BABILIDADES & $77 \%$ \\
\hline Capacidade de comunicação & $69 \%$ \\
\hline Trabalhar sob pressão & $54 \%$ \\
\hline Boa Memória & $51 \%$ \\
\hline Capacidade de síntese de ideias & $51 \%$ \\
\hline Capacidade de tomar decisões & $49 \%$ \\
\hline Dirigir veículos & $46 \%$ \\
\hline
\end{tabular}




\begin{tabular}{|l|c|}
\hline $\begin{array}{l}\text { Elaboração de relatórios, Capacidade de aprendizagem contínua, Capacidade de inovar, } \\
\text { Capacidade de criar, Senso de organização, Trabalho em equipe, dedicação integral, } \\
\text { Concentração, Raciocínio Lógico. }\end{array}$ & Menor que $40 \%$ \\
\hline \multicolumn{1}{|c|}{ ATITUDES } & Importância \% \\
\hline \multicolumn{1}{|c|}{ Empatia } & $54 \%$ \\
\hline Ética Profissional & $54 \%$ \\
\hline Iniciativa & $54 \%$ \\
\hline Integridade & $49 \%$ \\
\hline $\begin{array}{l}\text { Motivação } \\
\text { Elexibilidade, Boa Apresentação Pessoal, Espírito de Equipe, Postura Profissional, } \\
\text { Paciência. }\end{array}$ & Menor que $40 \%$ \\
\hline
\end{tabular}

\section{Fonte: Dos autores.}

\subsection{Competências identificadas no brainstorming}

Ao se avaliar os resultados obtidos do brainstorming foram identificadas 38 competências, sendo 8 no quesito conhecimentos, 11 no quesito habilidades, 19 no quesito atitudes. Destas competências identificadas no Brainstorming, destacam-se 10 que foram as com maiores percentuais de relevância atribuídos pelos propagandistas de medicamentos, obtendo frequência superior a $30 \%$.

Ao se analisar estas competências de acordo com os quesitos: conhecimentos; habilidades; e atitudes foram obtidos os resultados apresentados no Quadro 3. Outro ponto interessante a destacar é que competência que obteve o maior escore foi trabalhar sob pressão, que foi citada por $42 \%$ dos participantes, sendo considerada a mais relevante.

Quadro 3: Demonstrativo do brainstorming dos propagandistas

\begin{tabular}{|l|c|}
\hline \multicolumn{1}{|c|}{ CONHECIMENTOS } & Importância \% \\
\hline Saber se Comunicar & $33 \%$ \\
\hline Relações Humanas & $33 \%$ \\
\hline Técnicas de Vendas & $33 \%$ \\
\hline Informática e Internet & $25 \%$ \\
\hline Saber Negociar & $25 \%$ \\
\hline Planejamento & $25 \%$ \\
\hline Língua Estrangeira, Bom Português. & Menor que 20\% \\
\hline \multicolumn{1}{|c|}{ HABILIDADES } & Importância \% \\
\hline Trabalhar sob pressão & $42 \%$ \\
\hline Boas relações humanas & $33 \%$ \\
\hline Capacidade de comunicação & $33 \%$ \\
\hline Dirigir veículos & $33 \%$ \\
\hline Trabalho em equipe & $25 \%$ \\
\hline Capacidade de tomar decisões & $25 \%$ \\
\hline Elaboração de relatórios & $25 \%$ \\
\hline Senso de organização, boa memória, criatividade, dedicação integral. & Menor que 20\% \\
\hline \multicolumn{1}{|c|}{ ATITUDES } & Importância \% \\
\hline Comprometimento & $33 \%$ \\
\hline Empatia & $33 \%$ \\
\hline Entusiasmo & $33 \%$ \\
\hline Boa Apresentação Pessoal & $25 \%$ \\
\hline Disciplina & $25 \%$ \\
\hline Ética Profissional & \\
\hline
\end{tabular}




\begin{tabular}{|l|c|}
\hline Responsabilidade & $25 \%$ \\
\hline Integridade & $25 \%$ \\
\hline Motivação & $25 \%$ \\
\hline $\begin{array}{l}\text { Bom Senso, concentração, flexibilidade, iniciativa, dedicação, postura profissional, } \\
\text { espírito de equipe, força de vontade, ambição, paciência. }\end{array}$ & Menor que 20\% \\
\hline
\end{tabular}

Fonte: Brainstorming com propagandistas de medicamentos.

No quesito: conhecimentos 3 competências foram consideradas mais relevantes: relações humanas, técnicas de vendas e saber se comunicar.

Os resultados mostraram que os propagandistas atribuíram mais importância a algumas competências, a saber: relações humanas, técnicas de vendas, saber se comunicar, dirigir veículos, trabalhar sob pressão, comprometimento, empatia e entusiasmo.

Nesta técnica também foi observada a importância atribuída a técnica de vendas e relações humanas, observando que estes profissionais encaram suas atividades como uma atividade mercantil, isto é, atividade com um fim comercial, e no caso da indústria farmacêutica levam informações sobre doenças, tratamentos, produtos e serviços, visando ganhar a confiança destes prescritores, que influenciam de forma direta os consumidores, os pacientes Ainda que foram citadas também: relacionamento pessoal e capacidade de comunicação, que são competências complementares as já mencionadas anteriormente, saber se comunicar e ter conhecimento de relações humanas.

É interessante destacar, a importância do conhecimento em uma língua estrangeira, preferencialmente o Inglês. Percebe-se que muitas empresas são de origem multinacional e desejam que seus funcionários possuam estas competências, pois num mundo globalizado a capacidade de relacionamento com pessoas de diversas culturas, é um fator muito forte na adaptação, até porque que estas empresas utilizam estudos internacionais, e termos técnicos em inglês.

Assim, como algumas destas empresas já oferecem oportunidades de levarem seus melhores funcionários para participarem de reuniões fora do país, assim como para promovê-los a funções de gestão, e nestes casos o inglês é essencial, já que existe a necessidade destes gestores participarem de reuniões com diretores das empresas, e até mesmo com acionistas, e que boa parte deles são estrangeiros.

No quesito Habilidades as competências trabalhar sob pressão, boas relações humanas e capacidade de comunicação se destacaram, no nível de importância atribuído pelos propagandistas.

Trabalhar sobre pressão pode ser explicado, em razão do alto nível de exigência e acompanhamento dos resultados neste segmento, e ao fato das empresas estarem cada vez mais exigentes em relação à produtividade, destes profissionais, chegando inclusive a contratar empresas de auditoria para identificar os hábitos e as prescrições dos médicos, visando medir o impacto de suas estratégias e a eficiência das visitas de seus propagandistas aos médicos.

Já boas relações humanas e capacidade comunicação demonstram que os propagandistas de medicamentos acreditam estas habilidades são necessárias para influenciar e convencer os médicos, a ter uma conduta que favoreça aos seus interesses, isto é, prescreva os medicamentos que eles indicarem, através das visitas e das informações que fornecerem. 
No comparativo dos 2 instrumentos aplicados, foram extraídos os dados apresentados no Quadro 3, demonstrando 15 competências, divididas em conhecimentos, habilidades e atitudes, que foram citadas com maior relevância.

Conforme evidenciado por Fleury e Fleury (2004), as competências ligadas a Conhecimentos são aquelas ligadas ao saber fazer e ao conhecer, as ligadas as Habilidades são aquelas relacionadas a ser capaz de fazer, e as competências identificadas com o quesito atitude são aquelas que demonstram a capacidade de realizar e demonstram hábitos das pessoas.

A pesquisa apontou ainda que as competências técnicas de vendas, boas relações humanas, saber se comunicar ou capacidade de comunicação e trabalhar sob pressão foram as citadas com maior relevância em ambos os procedimentos.

Identificou-se que a competência considerada mais relevante em ambos os instrumentos de pesquisa foi técnicas de vendas. Este resultado indica que o conhecimento das técnicas de vendas é essencial para o bom desempenho desta profissão, conforme evidenciado por (BRODY, 2005; MEDAWAR, 2002; WAZANA, 2000; MAGUIRE, 1999; NORRIS, 2007), em estudos já realizados. Esta competência relacionada com as atividades de vendas: conhecimento das necessidades dos clientes, benefícios e vantagens do produto e ser capaz de manter relações comerciais com os médicos.

Técnicas de planejamento e de negociação são competências associadas a saber fazer, conhecer. Saber planejar e negociar estão ligadas ao dia-a-dia dos propagandistas, que antes das visitas, precisam planejar, as chamadas "pré-visitas", com os roteiros diários e semanais e o perfil do seu cliente. Já o conhecimento das técnicas de negociação, é necessário para que os propagandistas contornem os questionamentos e convençam os médicos a prescreverm seus medicamentos.

O estudo demonstrou que o propagandista de medicamentos deve ser capaz de falar e escrever num idioma diferente do seu, visto que a maior parte das empresas farmacêuticas é multinacional, além do domínio das ferramentas de informática e internet que são essenciais, para comunicação e pesquisas.

As competências boas relações humanas, boa memória, capacidade de comunicação, trabalhar sob pressão e capacidade de tomar decisões se destacaram como aquelas mais relevantes no quesito habilidades, em ambos procedimentos. Estes resultados demonstram que além de saber fazer, os propagandistas precisam ter a habilidade de fazer, e estas competências citadas evidenciam a importância da construção e manutenção de boas relações com os médicos e pessoas envolvidas nestas relações.

Para serem capazes de transferir conhecimentos os profissionais precisam ler bastante, estudar e reter conhecimento de forma constante e contínua, portanto, ter uma boa memória é relevante. Para a construção de boas relações humanas e para conseguir transferir de forma mais eficaz e efetiva o conhecimento é preciso ser capaz de se comunicar bem.

A propaganda médica é uma profissão em que os profissionais transferem informações sobre doenças e medicamentos, e neste caso é fundamental ter a habilidade de criar e manter boas relações com as pessoas, e se comunicar de forma clara e objetiva. Estes relacionamentos entre 
médicos e propagandistas são construídos diariamente através de respeito e de condutas éticas, baseados em empatia, integridade, neste sentido. (PALACIOS 2008).

Vale ainda ressaltar que as competências empatia, integridade e ética profissional, que estão ligadas a conduta dos profissionais também foram citadas com relevância em ambos os procedimentos, demonstrando a preocupação destes profissionais com relação à questão do comportamento e da sua conduta profissional.

Quadro 4: Competências mais relevantes identificadas em ambos os instrumentos (entrevistas e brainstorming).

\begin{tabular}{|c|c|c|}
\hline CONHECIMENTOS & HABILIDADES & ATITUDES \\
\hline Técnicas de Vendas & Boas relações humanas & Empatia \\
\hline Técnicas de Planejamento & Boa memória & Iniciativa \\
\hline Técnicas de Negociação & Capacidade de comunicação & Integridade \\
\hline Língua estrangeira & Trabalhar sob pressão & Motivação \\
\hline Informática e Internet & Capacidade de tomar decisões & . \\
\hline
\end{tabular}

Fonte: Dos autores.

Neste sentido ter empatia, e ética profissional nas relações com os médicos evidencia a importância da conduta ética, visto que nestas relações comerciais, científicas e pessoais há um risco de conflito de interesses, conforme evidenciado por Wazana (2002) e Norris et al., (2007). Assim sendo a competência integridade, que significa ser integro, ter conduta correta também surge com relevância na visão dos propagandistas.

\section{CONSIDERAÇÕES FINAIS}

O estudo identificou as competências essenciais aos profissionais propagandistas vendedores de medicamentos da indústria farmacêutica que atuam em Natal, na perspectiva dos mesmos. Ao todo foram identificadas 46 competências, das quais 35 foram citadas nos dois procedimentos de pesquisa, e 15 competências foram as que os propagandistas atribuíram maior importância.

Estas competências foram: técnicas de vendas, técnicas de planejamento, técnicas de negociação, língua estrangeira, informática e internet, boas relações humanas, boa memória, capacidade de comunicação, trabalhar sob pressão, capacidade de tomar decisões, empatia, ética profissional, iniciativa, integridade, motivação.

Neste sentido, as competências foram identificadas e divididas em Conhecimentos, habilidades e atitudes, conforme quadro 3. O conhecimento das técnicas de vendas, técnicas de negociação e técnicas de planejamento, competências relacionadas com o saber fazer, e as atividades diárias dos propagandistas de medicamentos, que precisam planejar o seu trabalho, saber negociar e saber identificar as necessidades de seus clientes, e demonstrar as vantagens e benefícios dos produtos que ele está promovendo.

Para isso, é preciso ter a habilidade de criar e manter boas relações humanas, ser capaz de se comunicar de forma clara e objetiva, e trabalhar sob pressão, em razão da alta competição deste mercado. E assim sendo algumas atitudes demonstraram ser essenciais para isso: A empatia, a ética profissional e a integridade que são competências ligadas ao comportamento e as condutas. 
Dentre estas se identificou aquelas que estão mais ligadas aos profissionais, a sua formação educacional e familiar, isto é as competências individuais, que neste caso são: A Empatia, Ética Profissional, Iniciativa, integridade e ainda a caracterização do trabalho e das atividades diárias dos profissionais que atuam na propaganda médica, visitando e promovendo produtos farmacêuticos aos profissionais de saúde, usando suas técnicas de propaganda, seus equipamentos de tecnologia da informação e negociando a com seus clientes, em busca da prescrição.

Observou-se ainda, que estes profissionais em suas atividades diárias desempenham atividades de bastante complexidade, que exigem o uso destas competências para o alcance dos objetivos pré-estabelecidos, através das metas que a eles são impostas pelas empresas farmacêuticas. Neste sentido, as suas atividades são caracterizadas como propaganda, marketing e venda.

Considera-se, portanto, que a identificação das competências essenciais da propaganda médica contribui de forma importante para que a indústria farmacêutica possa melhor estabelecer suas estratégias, comunica-la de forma mais eficiente à sua equipe, bem como para seus colaboradores, os propagandistas de medicamentos. Assim sendo é necessário que sejam desenvolvidos manuais de ensino, treinamentos e capacitações para que toda a força de vendas da indústria farmacêutica esteja mais consciente das competências essenciais necessárias para que os propagandistas farmacêuticos sejam mais competitivos e eficientes no exercício de sua profissão, contribuindo de para que a sua organização possa obter os melhores resultados possíveis, sendo agentes competentes para implementar as estratégias de marketing, propaganda e promoção de medicamentos planejadas pela organização.

Através deste trabalho percebe-se a importância que estes profissionais possuem para o alcance dos resultados da indústria farmacêutica, que realizar grandes investimentos em pesquisa, desenvolvimento, marketing e treinamento, e neste sentido acredita-se que é preciso aumentar os investimentos em treinamento e capacitação de seus colaboradores que atuam na propaganda médica, para torná-los cada vez mais capacitados e alinhados com as novas realidades deste mercado e com os objetivos organizacionais, e em especial o aumento dos seus lucros e da sua participação no mercado.

\section{REFERÊNCIAS}

1. BITENCOURT, C. C. Competência gerencial e aprendizagem nas organizações. São Leopoldo: Editora Unisinos, 2005.

2. BRASIL. Decreto no 79.094, de 5 de janeiro de 1977. Regulamenta a Lei no 6360, de 23 de setembro de 1976, que submete a sistema de vigilância sanitária os medicamentos, insumos, farmacêuticos, drogas, correlatos, cosméticos, produtos de higiene, saneantes e outros. Diário Oficial da União, Brasília, DF, 7 jan. 1977. Disponível em: <http://elegis.bvs.br/leisref/public/showAct.php?id=9331>. Acesso em: 07/01/2012.

3. BRASIL. Ministério da Saúde. Agência Nacional de Vigilância Sanitária. Resolução RDC no 102, de 30 de novembro de 2000. Disponível em: <http://elegis.bvs.br/leisref/public/showAct.php?id=11079>. Acesso em: 10/12/2012.

4. BRODY, H. The Company We Keep: Why Physicians Should Refuse to See Pharmaceutical 
Representatives. Annals fam medicine. vol. 3 no 1 - jan-feb: 82-86, 2005.

5. CIVANER, M. Sale strategies of pharmaceutical companies in a "pharmerging" country: The problems will not improve if the gaps remain. Health Policy 106 225-232, 2012.

6. DAVIES, I. A.; RYALS, L. J.; HOLT, S. Relationship management: A sales role, or a state of mind?: An investigation of functions and attitudes across a business-to-business sales force. Industrial Marketing Management, 39.7:1049-1062, 2010.

7. DAS, A. Pharmaceutical industry and the market: The case of Prozac and other Antidepressants. Asian Journal of Psychiatry 4 14-18 (2011).

8. DUTRA, J. S. Competências: conceitos e instrumentos para a gestão de pessoas na empresa moderna. São Paulo: Atlas, 2004.

9. FLEURY, M. T; FLEURY, A. Construindo o conceito de competência. Revista de Administração Contemporânea, Edição Especial, v. 5, p. 183-196, 2001.

10. FleURY, M. T; FleURY, A. Alinhando estratégias e competências. ERA - Revista de Administração de Empresas, vol. 44, n. 1, 2003.

11. FLEURY, M. T; M. T; FLEURY, A. Estratégias empresariais e formação de competências: um quebra-cabeça caleidoscópico da indústria brasileira. São Paulo: Atlas, 2004.

12. FUGH, B. A, AHARI S Following the Script: How Drug Reps Make Friends and Influence Doctors. PLoS Med 4(4): e150. doi:10.1371/journal.pmed.0040150, 2007

13. GAGNON M. A.; LEXCHIN J. The Cost of Pushing Pills: A New Estimate of Pharmaceutical Promotion Expenditures in the United States. PLoS Med 5(1): e1. doi:10.1371/journal.pmed.0050001, 2008

14. GREEN, K. W., WHITTEN, D., e INMAN, R. A. Aligning marketing strategies throughout the supply chain to enhance performance. Industrial Marketing Management. 41:1008-1018, 2012.

15. KHALIQ, M. J., ZIA-UR-REHMAN, M., \& RASHID, M.. The role of human resource management and nurses' job satisfaction in medical service organisations. AJBM, 5, 974-86, 2011.

16. KOBAYASHI, R. M. Desenvolvendo competências profissionais dos enfermeiros em serviço. Revista Brasileira de Enfermagem, vol. 63, n. 2, abril, 2010.

17. KREMER, S T. M.; BIJMOLT, T. H. A.; LEEFLANG, S.H. P ; WIERINGA, J. E. Generalizations on the effectiveness of pharmaceutical promotional expenditures. International Journal of Research in Marketing. 25 234-246. 2008.

18. LE BOTERF, G. Desenvolvendo a competência dos profissionais. 3. ed. Porto Alegre: Artmed, 2003.

19. MAGUIRE, P. How direct to consumer advertising is putting the squeeze on physicians American College of Physicians. American Society of Internal Medicine Observer March. 1999

20. MEDAWAR, C. Promotion of prescription drugs: trade tactics? Consumer Policy Review 12:1830, 2002.

21. MINTZBERG, H. AHLSTRAND; B., LAMPEL, J. QUINN, J. B. e GHOSHAL, S. O processo da estratégia: conceitos, contextos e casos selecionados. Porto Alegre: Bookman, 2008.

22. MOURA, M. C.; BITENCOURT, C. C. A articulação entre estratégia e o desenvolvimento de 
competências gerenciais. RAE-eletrônica, v. 5, n. 1, Art. 3, jan./jun. 2006.

23. NORRIS, P.; HERXHEIMER A.; LEXCHIN J.; MANSFIELD P. Drug promotion: what we know, what we have yet to learn (Reviews of materials in the WHO/HAI database on drug promotion), 2007.

24. PALÁCIOS, M.; REGO, S.; LINO, M. H. Promoção e propaganda de medicamentos em ambientes de ensino: Elementos para o debate. Interface. Comunicação, Saúde e Educação, v.12, n.27, p.895-908, 2008.

25. PORTER, M. E. Competitive strategy, New York: Free Press. 1980.

26. PRAHALAD, C. K.; HAMEL, G. Competindo pelo futuro: estratégias inovadoras para obter o controle do seu setor e criar os mercados de amanhã. Rio de Janeiro: Campus, 2004.

27. VergarA, S. C. Começando a definir a metodologia. In: em administração. 3. ed. São Paulo: Atlas, 2000. cap. 4, p. 46-53. Projetos e relatórios de pesquisa

28. WAZANA, A. Physicians and the pharmaceutical industry: Is a gift ever just a gift? J. Am. Med. Assoc., v. 283, n.3, p. 373-80, 2000.

29. WOOD JR., T.; PICARELLI-FILHO, V. Remuneração e carreira por habilidades e competências: preparando a organização para a era das empresas de conhecimento intensivo. 3. ed. rev e amp. São Paulo: Atlas, 2004.

30. WRIGHT, P. M., \& MCMAHAN, G. C. Exploring human capital: putting 'human'back into strategic human resource management. Human Resource Management Journal, 21(2), 93-104, 2011.

31. ZARIFIAN, F. Objetivo competência: por uma nova lógica. São Paulo: Atlas, 2001.

32. ZHOU, K. Z., BROWN, J. R., e DEV, C. S. Market orientation, competitive advantage, and performance: A demand-based perspective. Journal of business research, 62(11), 1063-1070, 2009. 